\title{
LA LECTURA DIALÓGICA: RED-DECIR EL TEXTO
}

\author{
Carlos Manuel Villalobos
}

\begin{abstract}
RESUMEN
En este artículo se parte de un supuesto cambio epistemológico en la crítica literaria. Se relacionan diversos conceptos teóricos y se proponen la lectura dialógica y el efecto de subjetividad del texto como códigos fundamentales del nuevo paradigma.
\end{abstract}

\begin{abstract}
An epistemological change in literary criticism constitutes the starting point for this article. Several theoretical concepts are related and dialogic reading and the effect of subjectivity are put forth as fundamental codes of the new paradigm.
\end{abstract}

\section{Intro-misión}

Desde 1966, Roland Barthes hablaba ya de una crisis general del Comentario. Para Barthes este fenómeno era tan significativo como el paso de la Edad Media al Renacimiento (1972: 50). Han pasado treinta años. ¿Han ocurrido los cambios tan significativos que predecía el famoso teórico francés? ¿Cómo afecta este proceso a los "Comentadores" que estudian los productos culturales justo al finalizar el segundo milenio oficial?

Sabemos que durante estos treinta años se han estado cuestionando las bases logocéntricas que han regido el pensamiento occidental. Se han roto cánones, se mira de reojo la dialéctica hegeliana, y con Heidegger y Nietzsche se han abrazado posiciones que relativizan el sentido.

La moda de esta época se llama post-(estructuralismo) (modernismo) (vanguardismo). (E incluso, algunos teóricos antiutopistas agregan post-historia). En este contexto, los comentadores de las prácticas culturales, llamados críticos, construyen discursos que se abren a la ambigüiedad. Y esta ruptura de la univocidad es quizá una las consecuencias más relevantes del cambio al que hacía alusión Barthes.

En diversos ámbitos académicos la búsqueda de significados unívocos se ha ido abandonando y en su lugar, se acepta que el sentido es un proceso abierto a la plurisignificatividad. 
En consecuencia, ¿cuáles son los códigos que debe conocer un "comentador de textos" en esta época? En otras preguntas: ¿Cómo leer? ¿Cómo comentar desde esta perspectiva?

\section{La paradoja del texto como dinamicidad}

La preocupación teórica que se plantea aquí tiene como objeto continuar una discusión que posee ya bastantes antecedentes en la teoría literaria y la filosofía de la estética. Se trata del problema de la interpretación o la crítica, sobre todo, a propósito de textos culturales como la literatura, el cine, los discursos políticos, etc. La apertura de nuevos puntos de vista sobre este tema ha hecho que no se encuentre una solución convincente; al contrario, cada vez parece más pantanoso buscar una respuesta sobre el método que asegure una interpretación coherente.

El estudioso de los textos estéticos tiene frente a sí un verdadero problema epistemológico que aún hoy no está suficientemente aclarado y más bien parece complicarse.

Los estructuralistas en su crítica al Formalismo Ruso planteaban que la obra no era tan estática, sin embargo, el método usado reducía su objeto a sentidos unívocos. Los telquelistas franceses se interesaron por el problema. Así, el texto, concepto axioma de la teoría semiótica de Julia Kristeva, es considerado como productividad que redistribuye el orden del discurso. Es sumamente dinámico y es capaz de producir significados cada vez que un lector lo enfrente.

Sin embargo, el resultado de esta lectura es la conformación de otro texto, que a su vez es productividad. Por lo tanto, puede ser objeto de otros análisis, que también son textos, y así hasta el infinito.

\section{Los contra(c)tos de la crítica y el texto}

La Sociocrítica sostiene que todo texto plantea un contrato de lectura, es decir, procura fijar los términos de la relación con el lector. Pero este con-trato no es legal, es ambiguo; y puede ser también contra-acto: contra el texto loco que contagia, contra su performancia que agrede.

El crítico literario también fija su con-trato (trato con (contra) el texto). Puede ser un trato dialógico que procura enfrentar el texto desde sus voces, es decir, desde su relación constitutiva con el texto general de la cultura; pero también puede ser monológico, es decir, hacerlo callar, que no hable porque no le conviene al poder. Esta última es por lo común una estrategia impresionista: emitir juicios de valor en concordancia con ciertos códigos morales y estéticos hegemónicos.

Generalmente el discurso lector (crítico) montado a propósito de un texto literario (convergencia de otros textos) resulta una búsqueda que procura rastrear otras anteriores. El escritor redistribuye los discursos de la historia que lo han socializado en determinado marco espacio-temporal y el crítico intenta dar cuenta de ello.

Sin embargo, el texto, en su estructura, es bastante complejo: 
... es un juego, un cambio constante, un movimiento hacia un fin jamás alcanzado, una aspiración hacia una finalidad defraudada (Kristeva 1974:22).

De acuerdo con el Semanálisis, el texto es objeto dinamizado "ni estructura significante, ni productividad significativa, sino ambas cosas" (Pérez 1981: 64). Es un "proceso de mutación", que dice y se dice. Es uno frente al otro, y otro frente a sí mismo. Se desarrolla pulsionalmente.

La interpretación no podría ser, por lo tanto, un intento de aprehensión absoluta. Es necesario renunciar de una vez a este objetivo, pues se estaría comportando el proceso de lectura como una relación para identificar una esencialidad.

Si se toma en cuenta la dimensión sígnica, el significado, como apunta Jacques Derrida, deberá considerarse como un espacio vacío que puede ser llenado de múltiples maneras (Culler 1978: 34).

Estrategias recientes para el análisis del texto tales como el Semanálisis, la Sociocrítica y el Desconstruccionismo posibilitan respetar el estatus del texto, sin pretender reducirlo a un sentido unívoco.

Estas estrategias, a su vez, se complementan con una propuesta esbozada a principios de este siglo en la Ex-Unión Soviética. La hemos venido utilizando: el dialogismo bajtiniano. Aunque Mijaíl Bajtín la utilizó para referirse a la estructura de ciertos discursos literarios, Tzvetan Todorov la propone como una forma de leer. Se trata de una actitud ética que consiste en cederle la voz a las otredades, oír la época, la tradición, el proceso de producción. Y desde ahí, sin miramientos de complicidad hipócrita, convergir, divergir, combatir, desconstruir. Se trata entonces de investigar el texto y sus relaciones, seguirle la pista a la contradicción, a los no dichos ideológicos, a su condición de sujeto escindido por la tradición y el productor.

Para Todorov:

\footnotetext{
...la crítica dialógica habla, no acerca de las obras, sino a las obras o, más bien, con las obras; se niega a eliminar cualquiera de las dos voces en presencia. El texto criticado no es un objeto que deba asumir un "metalenguaje", sino un discurso que se encuentra con el crítico (1991:150).
}

Vistos como hablas, principalmente después de las estrategias estructuralistas iniciadas por Lévi-Strauss, el mito y el arte han sido reducidos a lecturas con actitud monológica. Esta consideración implicaba un serio problema epistemológico: ¿cómo decir de nuevo lo que ya se dijo? ¿Es esto interpretar? Esta paradoja de lo monológico no está del todo resuelta en la dimensión dialógica: ¿se puede redecir lo dicho? Una posible solución desde el dialogismo es el desdoblamiento: gesto ambiguo que a nivel léxico implica la estrategia de desdoblar el término redecir. Se trata entonces de red-decir el texto que como práctica significante, histórica y social constituye una red. Red-decir significa activar esa red que va desde un texto particular al texto general de la cultura. 


\title{
Texto: efecto de sujeto
}

\author{
"Ya no es posible seguir sosteniendo \\ la absoluta separación entre el sujeto y el objeto" \\ Ernesto Sábato.
}

Considerar el texto como objeto es colocarlo en una relación de poder, en la que presumiblemente dirá, si es que puede, lo que el sujeto crítico le pregunte. Un diálogo es una relación de sujeto a sujeto. Tanto el crítico, determinado por sus condiciones sociales como el texto están en condiciones de decir.

La teoría literaria ha aportado gran cantidad de estrategias para abordar su objeto, algunas incluso se han denominado a sí mismas métodos de análisis. En la base de cada una de estas propuestas hay consideraciones epistemológicas que las sustentan. Sin embargo, no hay un acuerdo a propósito de cómo debe ser la relación entre el sujeto crítico y este objeto de estudio, ya que el texto no tiene propiedades físicas o químicas como el objeto de otras disciplinas.

En este punto se presenta un problema: el carácter del texto y el carácter de la crítica. Ambos son discursos, construcciones lingüísticas, enunciados, prácticas significantes que se inscriben en determinadas coordenadas espacio temporales. Así, como ya se apuntó, cualquier discurso crítico puede ser objeto de análisis, y este análisis objeto de otro y así sucesivamente.

Las producciones significantes presentan problemas socioideológicos y trayectos de sentido que vienen desde múltiples redes. El texto es una presencia-ausencia de discursos. La organización morfosintáctica de una novela o una película o un anuncio publicitario, por ejemplo, es apenas la máscara de múltiples voces que se entretejen. ¿Cómo aprehender este objeto? ¿Se puede aprehender?

El Formalismo Ruso y luego el Estructuralismo Inmanentista criticaron fuertemente las lecturas idealistas e impresionistas por su falta de método. Después, el estructuralismo fue cuestionado por perder de vista la trascendencia significativa del texto. El estructuralismo trató de aprehender el texto como si fuera un objeto científico capaz de ser reducido a un sentido. Para ello propuso un método inmanente, y cientos de textos fueron sistematizados en estructuras fijas. Luego el Estructuralismo Genético trató de establecer la relación contextual, sin embargo el texto no pudo homologarse fácilmente a las estructuras sociales pues el lenguaje es una mediación y al mismo tiempo un recurso de virtualización de la "realidad".

Hay consenso entre los críticos post-estructuralistas en cuanto a que considerar el texto como objeto estático es negar su carácter. Se acepta entonces que el texto es un objeto dinámico. Si el texto dice, se significa constantemente, ¿cuál es la diferencia epistemológica con el concepto de sujeto? ¿Podría ser enfocado como otro sujeto discursivo? ¿Qué dificultades se oponen a la propuesta de esta pregunta? Para Manuel Picado, crítico costarricense, en la actitud del dialogismo la preocupación epistemológica tiene un sentido bastante amplio. Según Picado, de acuerdo con Bajtín, "el sujeto que conoce no se interroga a sí mismo ni a un tercero delante de una cosa muerta" (1985: 119).

El diálogo que puede montarse desde esta perspectiva es múltiple. Ya no será solo hablar sobre el texto, sino hablar al texto, con él, desde él, contra... Según Picado (1985) pueden utilizarse todas las preposiciones. 
La crítica, sin embargo, sigue teniendo en gran medida actitudes monológicas, sigue ajustándose a un paradigma metalingüístico desde el cual habla sobre el texto. De este modo continúa colocándolo en una relación de poder, sujeto frente a un objeto, donde este último dice a través de un método o estrategia previamente establecidos, lo que el sujeto crítico decida como último significado. Es más, las hipótesis iniciales de muchas tesis de grado universitario marcan de una vez lo que el sujeto quiere que el objeto diga. El método sirve para obligarlo a decir lo que el poder quiere.

Para Bajtín el dialogismo implica la participación de la voz de los "otros". Por lo tanto, las "relaciones dialógicas" son intersubjetivas. Proponer una lectura dialógica implica entonces considerar el carácter su(b)jetivo del texto; es decir, se debe partir de la capacidad de expresión del enunciado, donde es posible generar el diálogo: texto-lector. Sin embargo, este diálogo es asimétrico, pues a nivel fenotextual hay límites evidentes: el principio y el fin de la película, o el arriba y el abajo de la pintura. Mientras que los críticos podrán seguir a través de la historia de la humanidad.

Todorov plantea que para no hacer trampas en este juego asimétrico el crítico debe hacer escuchar la voz de su interlocutor (1991:150): obra, escritor, época, tradición, discursos, etc.

Por su parte, para Bajtín las "relaciones dialógicas" no se reducen a relaciones de lógica y significación que en sí mismas carecen de momento dialógico.

Deben ser investidas por la palabra, llegar a ser enunciados, llegar a ser proposiciones de diferentes sujetos, expresadas en la palabra, para que entre ellas puedan surgir dichas relaciones (Bajtín 1986: 256).

De este modo, para que surja la relación dialógica es necesario que los juicios se distribuyan entre dos diferentes enunciados de dos sujetos diversos.

Así pues, al plantear una lectura dialógica es necesario partir de los enunciados del texto, y desde ahí iniciar el enfrentamiento intersubjetivo. Sin embargo, ¿cómo no objetivizar el texto cuando se intenta enfrentarlo críticamente? De nuevo hay evidentes dificultades epistemológicas en esta propuesta. Para Manuel Picado tampoco en este caso habría problema pues el crítico abre el texto al juego. De este modo el texto no es una cosa estática que puede ser fácilmente objetivizada.

Este efecto de subjetividad del texto, sin embargo, no es nuevo. Jacques Derrida se lo había comentado a Julia Kristeva, a propósito de una entrevista que ella le hizo.

El efecto de la subjetividad del texto tal y como lo produce su estructura (sistema de relaciones) es inseparable de la sublimación y la pulsión de muerte (Derrida 1977:119).

Así pues, por diversas rutas se ha llegado a una paradoja: el texto es objeto pero también es sujeto. Esta consideración resulta sumamente importante, pues permite reflexionar sobre el instrumento epistemológico que se usa. Un texto particular es objeto y sujeto de conocimiento: (objeto de deseo y sujeto de relación con el Otro). El texto estético, narciso que centra la función del lenguaje sobre sí mismo, es deseado y se resiste. Se convierte entonces en un texto histérico y seductor. El discurso crítico no puede evitar objetivizarlo, y tiene conciencia de ello; pero los centros que va construyendo son relativos, y se diseminan constantemente a partir de la intertextualidad y dinamicidad que el texto (sujeto) produce. 


\section{Conclusión y más preguntas}

El texto como práctica significante y relacional no es un objeto estático que pueda ser aprehendido mediante un método. Al contrario, tal es su dinamicidad que ha sido necesario incluso cuestionar las bases mismas con las que tradicionalmente se hacen los comentarios de texto.

Frente a las paradojas del sujeto-objeto y mediación entre el crítico y la realidad, la crítica ha tenido que asumir una actitud intersubjetiva para enfrentar el texto estético, actitud que Bajtín empezó a delimitar cuando planteó la tipología monologismo vs. dialogismo.

No hay sin embargo, una respuesta última, porque la realidad muestra que la actitud monológica mantiene fuertes resabios ideológicos en la crítica de hoy. El dialogismo tal y como lo plantea Manuel Picado, se enfrenta a las trampas logocéntricas de la epistemología y no puede tan fácilmente salirse de la relación sujeto-objeto.

Los problemas que abre el dialogismo no están resueitos: ¿Desde dónde hablar cuando se dialoga con el texto desde el texto, y qué ocurre con los "no dichos" ideológicos del lector? ¿Cómo lograr un balance para que haya diálogo? ¿Cuáles instrumentos para verificar la coherencia exegética se deben usar? ¿O no se hablará más de interpretación, sino simplemente de ampliación de la red? ¿Y ampliar la red no es otra forma estructuralista de describir? ¿En cuántas trampas logocéntricas se ha caído y se caerá durante este proceso? Por ahora dejemos estas preguntas sueltas. Tal vez pronto encuentren otro preguntador que las dialogue.

\section{Bibliografia}

Bajtín, Mijaíl. 1986. Problemas de la poética de Dostoievski. Trad. Tatiana Bubnova. México: Fondo de Cultura Económica.

Barthes, Roland. 1987. Crítica y verdad. $3^{\text {a }}$ ed. México: Siglo XXI.

Culler, Jonathan. 1992. Sobre la deconstrucción. Trad. Luis Cremades. Madrid: Cátedra.

Derrida, Jacques. 1977. Posiciones. Trad. M. Arraz. Valencia: Editorial Pre-textos.

Kristeva, Julia. 1974. El texto de la novela. Trad. Jordi Llovet. Barcelona: Editorial Lumen.

Pérez, María. 1981. "La semiótica de la productividad y la teoría del texto en Julia Kristeva". Revista de Filología y Lingüística. 7 (1-2): 59-77.

Picado, Manuel. 1985. El envés de la red. San José: Editorial Universitaria Centroamericana.

Todorov, Tzvetan. 1991. La crítica de la crítica. Trad. José Sánchez. Barcelona: Ediciones Paidós. 